\title{
Electron microscopic study of the distribution of the Australia antigen in individual sera of 50 serologically positive blood donors and two patients with serum hepatitis
}

\author{
LINDA M. STANNARD, J. MOODIE, G. A. KEEN, AND A. KIPPS \\ From the MRC and University of Cape Town Virus Research Unit, Medical School, Cape Town
}

SYNOPSIS The distribution of the morphological types of Australia antigen in 50 blood donors and two patients with serum hepatitis is described.

The significance of the high incidence of immune complexes and Dane particles in these persistent carriers is discussed.

The morphology of Australia antigen has been studied extensively and the existence of three morphological components in serum has been established. These consist of roughly spherical particles about $20 \mathrm{~nm}$ in diameter (range 16-25 nm), tubules of the same diameter but varying up to several hundred nanometers in length, and the larger double-shelled spherical 'Dane' particles (Dane, Cameron, and Briggs, 1970) with an outer diameter of $42 \mathrm{~nm}$ (range 40-45 $\mathrm{nm}$ ) and an inner component with diameter of approximately $28 \mathrm{~nm}$. These $28 \mathrm{~nm}$ cores have been shown to be antigenically distinct (Almeida, Rubenstein, and Stott, 1971) and particles resembling them have been seen in liver homogenates from patients with serum hepatitis (Almeida, Waterson, Trowell, and Neale, 1970; Deutsch and Spence, 1972).

The simple technique of negative staining in electron microscopy was used to examine plasma samples from 50 Australia antigen-positive blood donors and to gain an impression of the relative distribution of the morphological components of antigen and the presence or absence of antigenantibody aggregates in these people. The opportunity also arose to examine sera from two patients who had contracted serum hepatitis. With the aid of the electron microscope we were able to follow the appearance of Australia antigen in the sera of the latter two patients during the course of their illness.

Received for publication 13 December 1972.
Materials and Methods

PLASMA AND SERUM SAMPLES

Fifty plasma samples from 'healthy' white, Coloured, and African blood donors whose blood was found to be Australia antigen-positive by an immunoelectrophoresis screening technique were examined by electron microscopy immediately upon receipt and after varying periods of storage at $4^{\circ} \mathrm{C}$ up to six months. Serial serum samples were obtained from two patients with serum hepatitis.

\section{ELECTRON MICROSCOPY}

Aliquots of $0.5 \mathrm{ml}$ of each plasma or serum were diluted with phosphate buffer ( $\mathrm{pH} \mathrm{7.0)}$ to $4.5 \mathrm{ml}$. These were clarified by centrifugation at $12000 \times g$ for 10 minutes and the supernatant fluids centrifuged at $50000 \times g$ for 60 minutes. The resulting pellets were washed once, negatively stained with $2 \%$ phosphotungstic acid ( $\mathrm{pH}$ 6.0), and examined in a Siemens Elmiskop 1A electron microscope.

\section{Results}

\section{BLOOD DONORS}

Electron microscopy showed the presence of particles of Australia antigen in 47 of the 50 plasma samples from blood donors selected for study on the basis of a positive serological test for Australia antigen. The antigen was found to be present in varying amounts ranging from just a few scattered 
$20 \mathrm{~nm}$ spherical particles to vast quantities of antigen comprising $20 \mathrm{~nm}$ spheres, tubules, and $42 \mathrm{~nm}$ Dane particles in varying proportion.

In samples with observable Australia antigen, spheres were invariably present and in a few cases this was the only morphological form of the antigen to be seen; but in most of the samples tubules were present as well. In $20 \%$ of the samples there was a predominance of the small spheres (fig 1) and in an equal number of cases there was a predominance of tubules (fig 2). The tubules frequently displayed bulbous ends or constrictions along their length suggesting that they break up into shorter tubules and spheres (fig 3).

The Dane particles were not always found. They were encountered in $30 \%$ of samples and in large numbers (such as fig 5 ) in four cases $(8 \%)$. They were easily identified by their size and structure and in many the outer shell was penetrated by the stain to reveal the inner component with a diameter of 27 to $28 \mathrm{~nm}$. On occasion, attached to the outer shell of the Dane particles there was a tail or projection morphologically identical with the free lying tubules (figs 4 and 5, arrows).

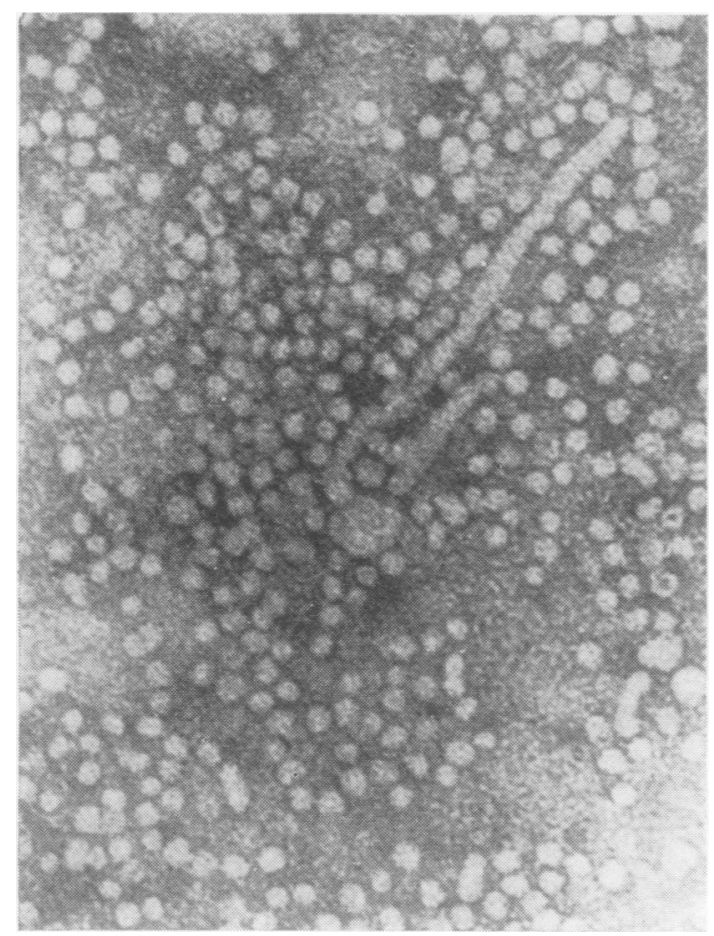

Fig. 1 A predominance of $20 \mathrm{~nm}$ spherical particles. $\times 110000$
In $50 \%$ of the plasma samples from blood donors을 antigen-antibody complexes were present (figs 4-8) $\Rightarrow$ but in the other $50 \%$ the antigen had a random? distribution (fig 6). The complexes varied con-음 siderably in size and on occasion reached dimensions $\frac{\bar{c}}{\bar{c}}$. of up to several microns. These were naturally? occurring aggregates (since no antibody was added $\varnothing$ to any of the plasma samples under examination in this study) but were indistinguishable from com- $\overrightarrow{0}$ plexes formed by the addition of specific antibody:to plasma containing Australia antigen which was $\vec{\omega}$ otherwise randomly distributed.

Aggregates contained $20 \mathrm{~nm}$ spheres, tubules, and? Dane particles, but it was of interest to note that $\tilde{\sigma}^{\circ}$ when aggregates were found in plasma samples with $\omega$ large numbers of Dane particles the complexes 0 frequently appeared to consist predominantly of Dane particles and tubules with very few $20 \mathrm{~nm}$ 을 spheres (figs 3, 4, and 5).

Three of the plasma samples examined were from donors who had been implicated in the transmission of serum hepatitis. No common pattern of distribution of the Australia antigen particles was seen. One patient had a random distribution of antigen ${ }^{\omega}$

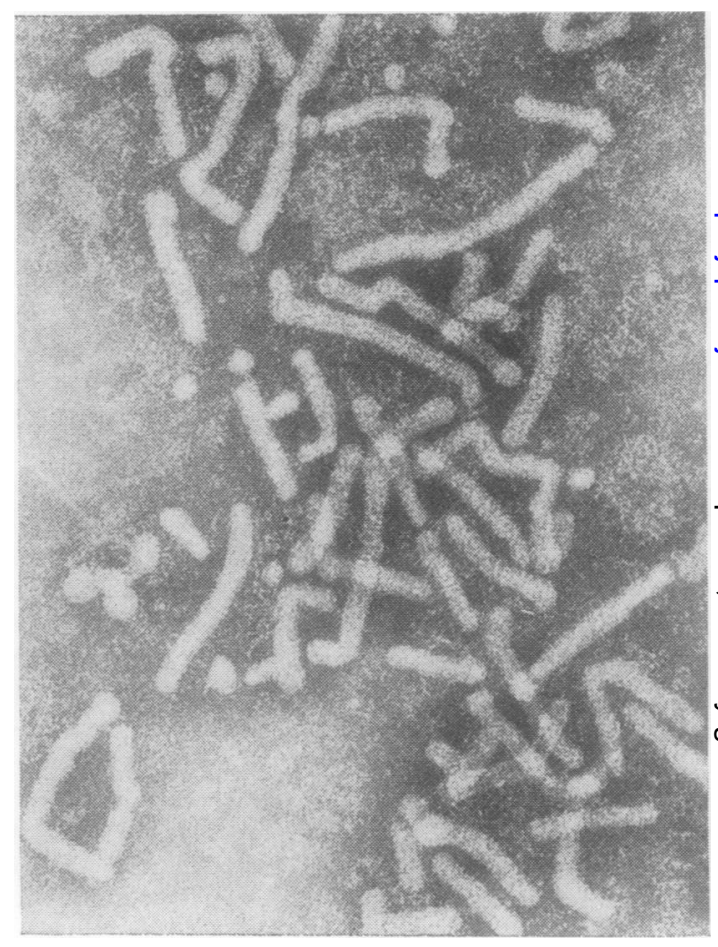

Fig. 2 A predominance of tubules. $\times 110000$ 


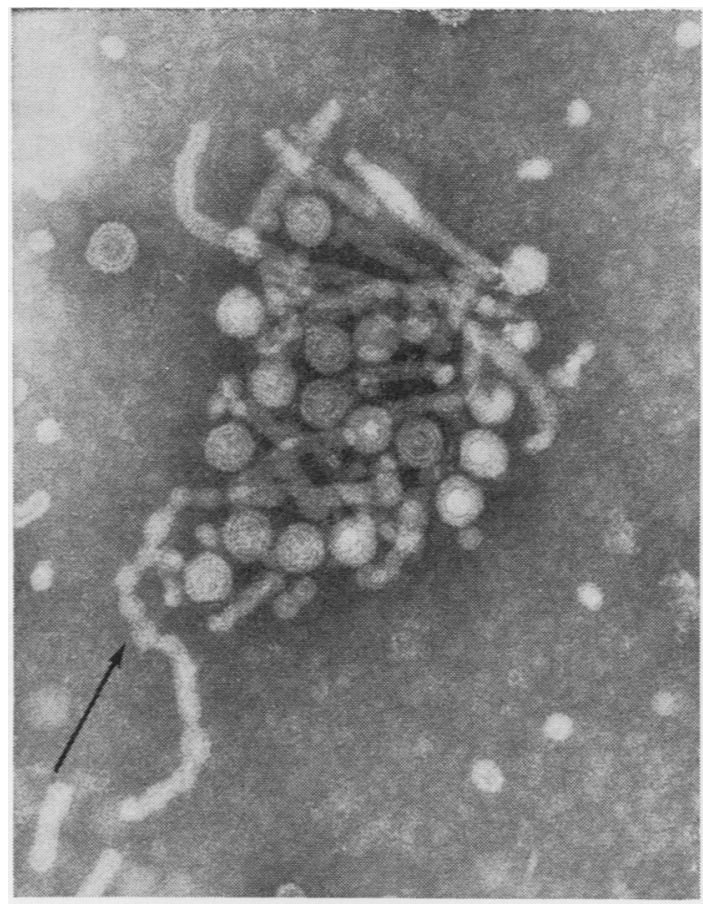

Fig. 3 Aggregate containing Dane particles and tubules. Arrow shows a tubule displaying prominent constrictions along its length. $\times 110000$

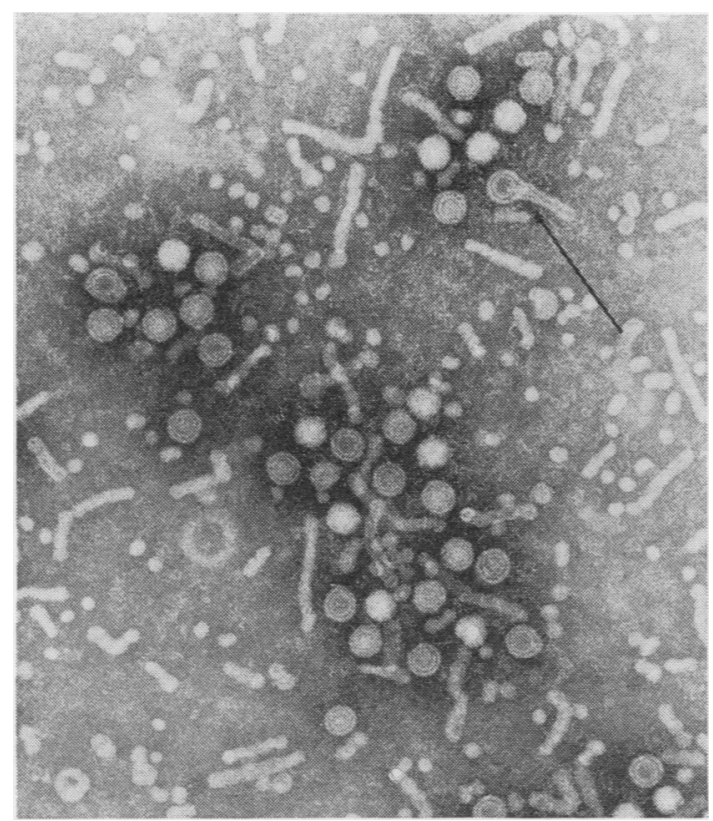

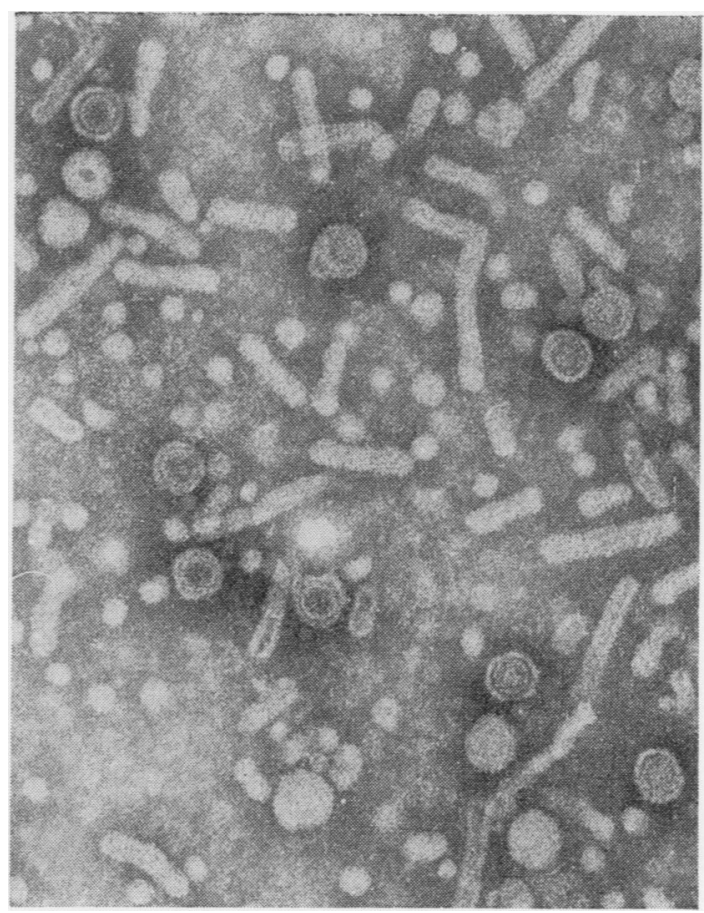

Fig. 6 A random distribution of all three morphological forms of Australia antigen. $\times 110000$

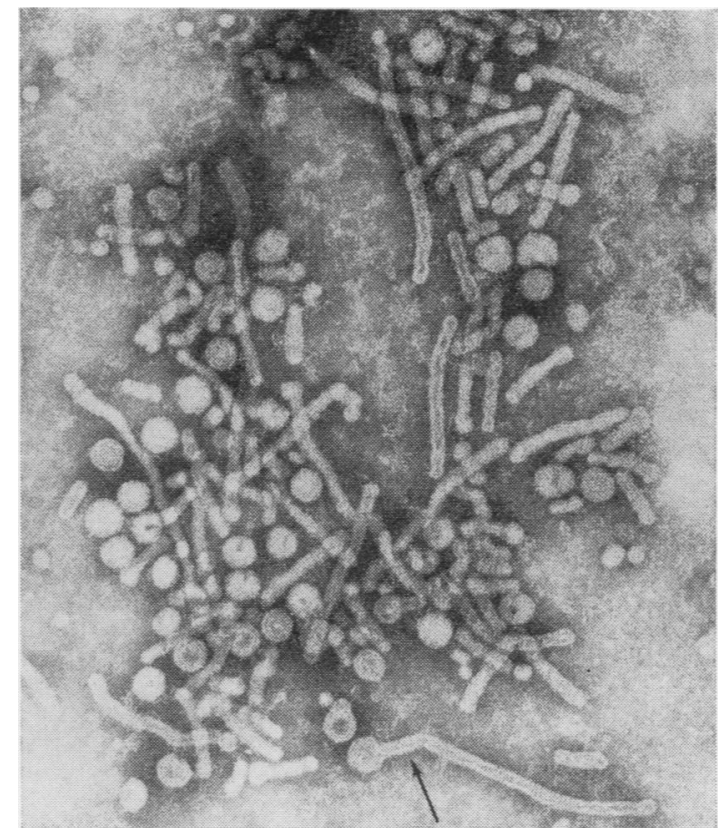

Figs. 4 and 5 Aggregates consisting predominantly of Dane particles and tubules while smaller $20 \mathrm{~nm}$ spheres remain mainly unaggregated. Arrows indicate Dane particles with tail-like projections similar to tubules. $\times 70000$ 


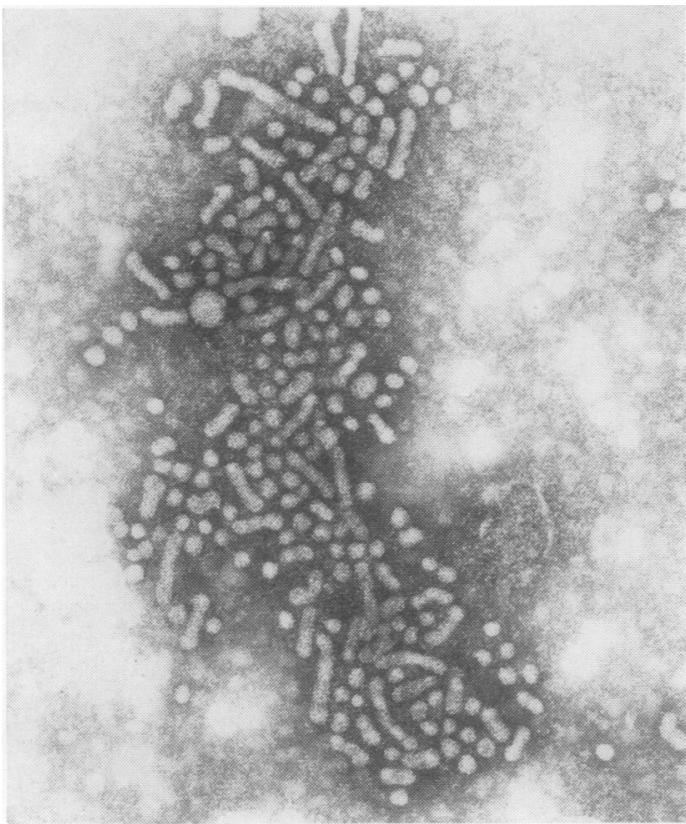

Fig. 7 Plasma sample with few Dane particles contains aggregates comprising all three morphological forms of Australia antigen. $\times 70000$

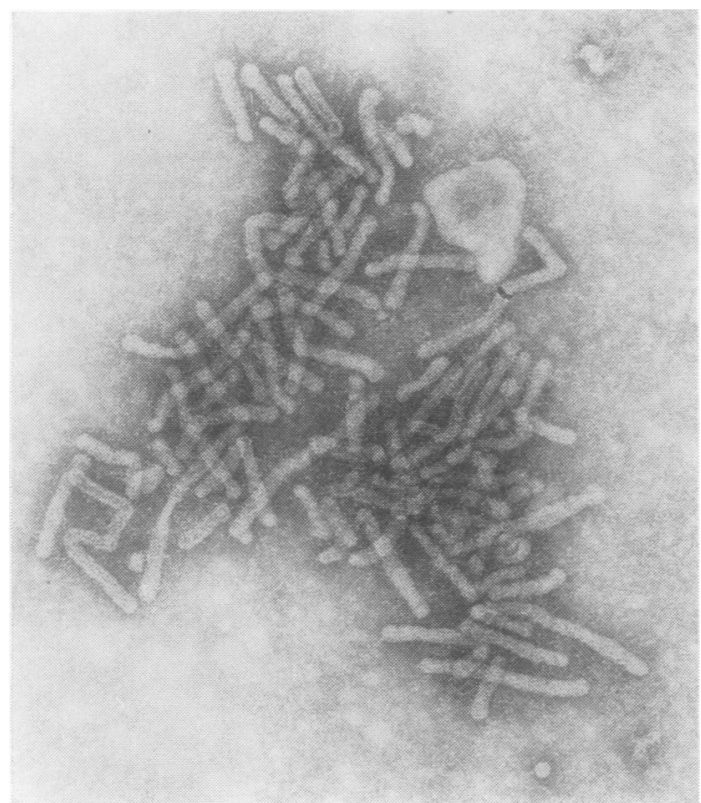

Fig. 8 Aggregate containing predominantly rods. $\times 70000$ containing numerous Dane particles, small spheres, $\stackrel{\stackrel{0}{*}}{\stackrel{5}{\circ}}$ and tubules. Of the other two patients, cnly one 은 showed Dane particles but both had antigen- $\frac{\vec{s}}{\sqrt{S}}$ antibody complexes (table I).

\begin{tabular}{llllll}
\hline Patient & $20 \mathrm{~nm}$ & & & \multicolumn{2}{l}{$42 \mathrm{~nm}$} \\
\cline { 2 - 3 } \cline { 6 - 6 } & Spheres & Tubules & & Spheres & Aggregates \\
\hline 1 & ++ & + & & + & - \\
2 & + & + & & - & + \\
3 & - & - & & + & + \\
\hline
\end{tabular}

Table I Distribution of Australia antigen in the plasma of three donors implicated in the transmission of serum hepatitis

During the course of examination of plasma is samples from blood donors, particles with a mor- 6 phology commonly likened to that of paramyxo- 윽

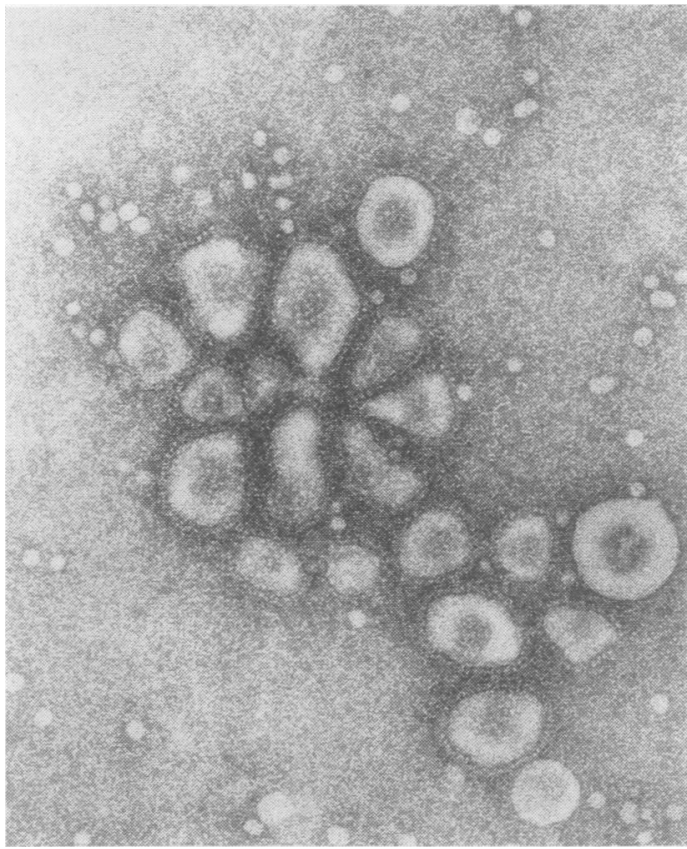

Fig. 9 A cluster of particles with morphology similar to that of myxo- or coronaviruses, surrounded by scattered Australia antigen components. $\times 80000$

viruses and coronaviruses were observed in many? instances. All three seropositive blood donors with $\frac{0}{0}$ no visible Australia antigen had these particles in $\vec{D}$ their sera. The 'coronavirus-like' particles, whatever $\frac{\stackrel{?}{\mathbb{D}}}{\mathrm{D}}$ their nature, usually appeared in clusters apparently응 linked by antibody (fig 9). 


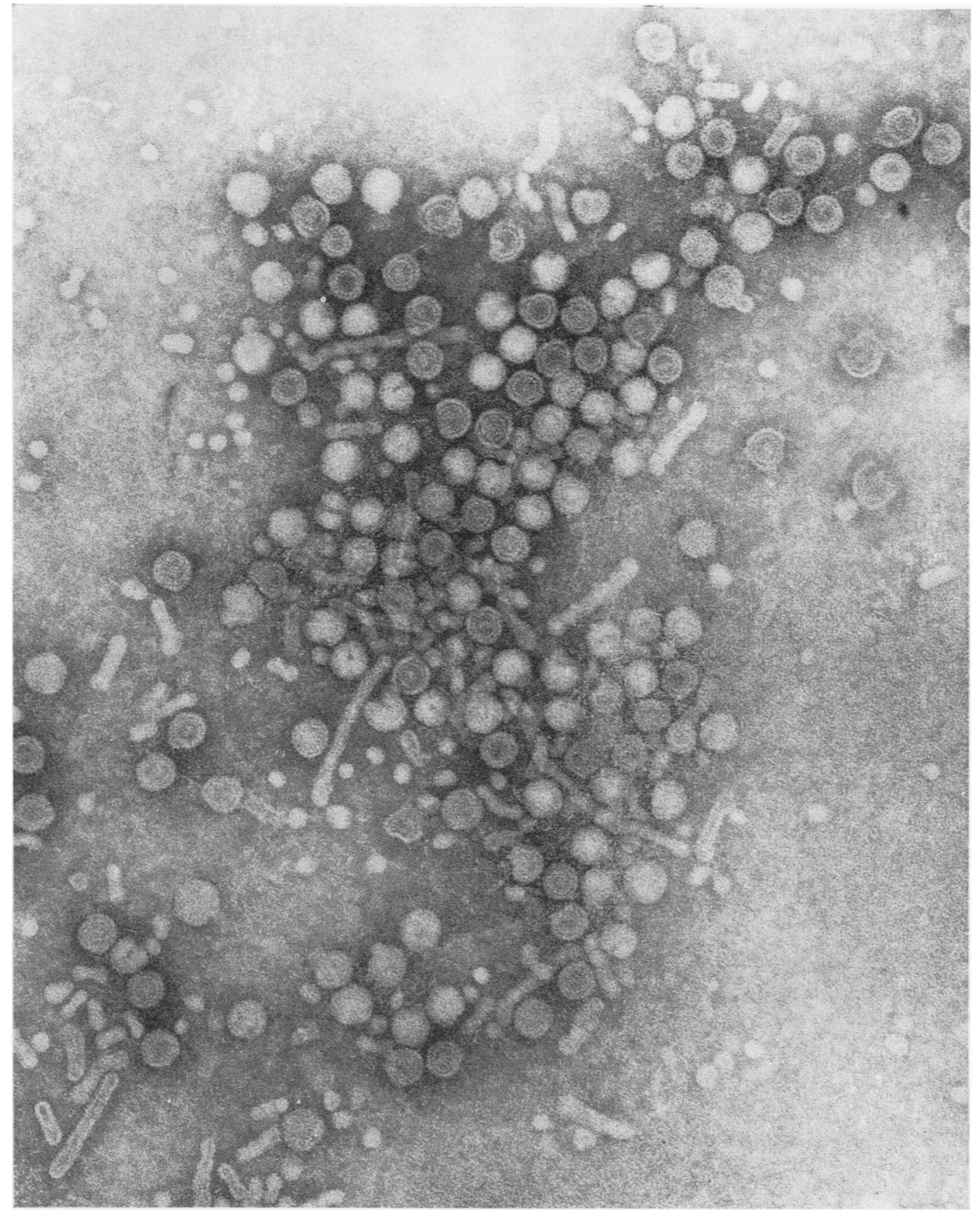

Fig. 10 Large cluster of Dane particles seen in the serum of patient $B$ two weeks after the onset of serum hepatitis. Small spheres remained unaggregated. $\times 120000$ 
PATIENTS WITH SERUM HEPATITIS

We were able to examine serial serum samples from two patients suffering from serum hepatitis and to follow the appearance and disappearance of the various morphological components of Australia antigen (table II).

\begin{tabular}{|c|c|c|c|c|c|}
\hline \multirow[t]{2}{*}{ Patient } & \multirow{2}{*}{$\begin{array}{l}\text { Day after } \\
\text { Onset of } \\
\text { Illness }\end{array}$} & \multicolumn{2}{|l|}{$20 \mathrm{~nm}$} & \multicolumn{2}{|l|}{$42 \mathrm{~nm}$} \\
\hline & & Spheres & Tubules & Spheres & Aggregates \\
\hline A & $\begin{array}{r}0 \\
10 \\
17 \\
32 \\
47\end{array}$ & $\begin{array}{l}+ \\
++ \\
+- \\
+ \\
+\end{array}$ & $\begin{array}{l} \pm \\
- \\
- \\
- \\
-\end{array}$ & $\begin{array}{l}- \\
- \\
- \\
-\end{array}$ & $\begin{array}{l}- \\
++ \\
+ \\
-\end{array}$ \\
\hline B & $\begin{array}{r}14 \\
21 \\
28 \\
34 \\
252\end{array}$ & $\begin{array}{l}++ \\
++ \\
++ \\
+ \\
+\end{array}$ & $\begin{array}{l}++ \\
= \\
- \\
-\end{array}$ & $\begin{array}{l}+ \\
\pm \\
- \\
- \\
-\end{array}$ & $\begin{array}{l}+1 \\
+ \\
- \\
+ \\
-\end{array}$ \\
\hline
\end{tabular}

Table II The appearance of Australia antigen in the serum of two patients with serum hepatitis

Patient A was a staff member of a large blood transfusion organization. The first sample was taken at the onset of illness. At this stage the Australia antigen was randomly distributed and consisted almost entirely of small spheres (20-22 nm) with only occasional short tubules. No Dane particles were seen. Ten days later the small spherical particles were more numerous, occurring mainly in aggregates, and there were no rods. A week later fewer aggregates were visible in the patient's serum and the scattered antigen particles still consisted solely of small spheres. Serum samples examined at weekly intervals over the following month showed a steady decrease in the number of antigen particles present and by the 47 th day of clinical illness the serum no longer contained detectable Australia antigen components by the electron microscopic technique used in this study.

Patient $B$ received 6 units of plasma and 2 units of blood in four weeks of postoperative care, three to four months before the onset of jaundice. Serum taken two weeks after the first signs of jaundice revealed large quantities of Australia antigen consisting of small spheres, tubules, and Dane particles. It was a striking observation that the Dane particles appeared together in large clusters, associated with relatively few tubules and small spheres, since most of the two smaller components remained unaggregated (fig 10).

Seven days later very few Dane particles or tubules were observed in the patient's serum. The Australia antigen present now consisted predominantly of $20 \mathrm{~nm}$ spheres, many of which appeared in tight

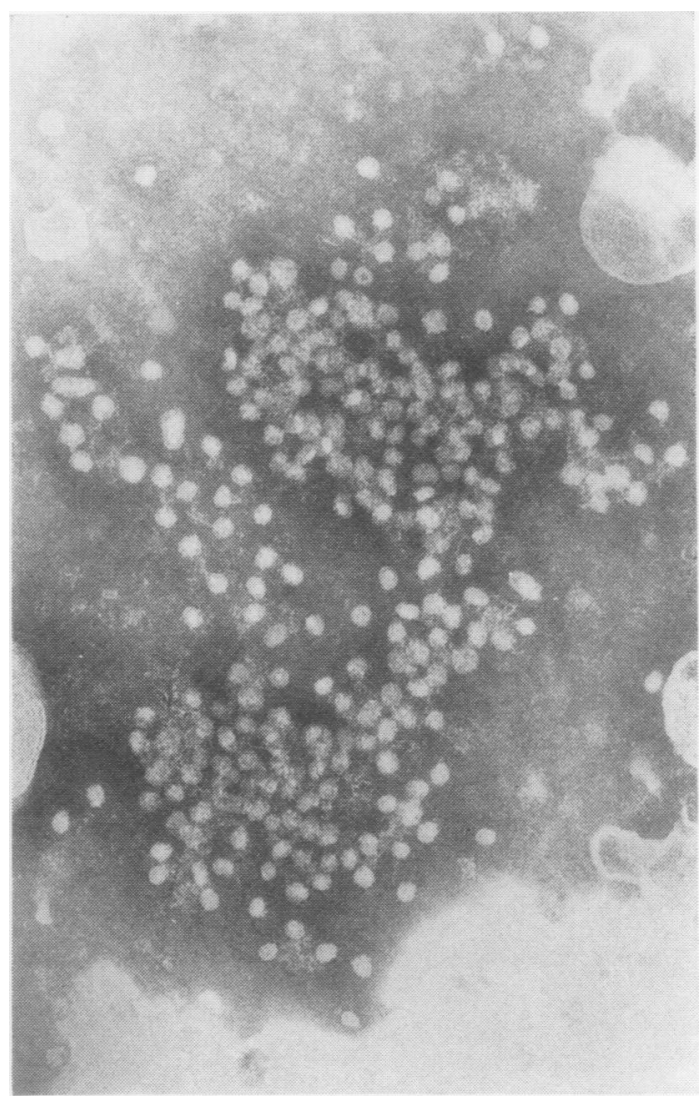

Fig. 11 Serum of patient B three weeks after the onset of serum hepatitis contained predominantly small spheres, and many tight aggregates. $\times 90000$

aggregates (fig 11) resembling the antigen-antibod complexes produced by the addition of specifie antiserum. By the end of the following week thes aggregates had disappeared leaving only randoml scattered small spheres. Six days later aggregates were once more very much in evidence and the complexes were strikingly large and dense.

In all serum samples from both patients $A$ and $B_{\text {A }}$ occasional groups of the coronavirus-like particles were seen.

\section{Discussion}

The presence of Australia antigen in 50 "healthy" blood donors found to be serologically positive b5 immunoelectrophoresis was confirmed by electror microscopy in $47(94 \%)$ of the plasma sample examined by a simple technique. The procedure therefore is a reasonably sensitive one and it is quite 
possible that antigen would have been seen in the three remaining samples had greater concentration of the plasma been attempted.

Antigen particles varied very considerably in relative proportion and in amount and the morphology was identical with that described by Bayer, Blumberg, and Werner (1968), Almeida, Zuckerman, Taylor, and Waterson (1969), Dane et al (1970), and Almeida (1972). If the Dane particles prove to be the infectious virus particles it is noteworthy that at least $30 \%$ of these donors had virus particles in their blood. Furthermore $50 \%$ of these blood samples were shown to have visible aggregates resembling antigen-antibody complexes. There was no common pattern of distribution of the antigen particles in the blood of three donors thought to have been responsible for causing serum hepatitis in three recipient patients.

The morphological components of Australia antigen in some of the immune complexes deserve special mention. It was consistently noted that in plasma samples with large numbers of Dane particles the aggregates were predominantly of Dane particles and tubules while the small spheres remained randomly scattered. Similar observations were made by Zalan, Hamvas, Tobe, Kuderewko, and Labzoffoky (1971). It was often difficult to identify linking antibody molecules with any confidence but naturally occurring aggregates had the appearance of loose clusters not as tightly clumped as the complexes formed by the addition of specific antibody. They are not produced by prolonged storage, since plasma samples without aggregates or clusters have been show to remain free of them by repeated examination over a period of months, nor are they caused by packing in the centrifuge, since velocities far in excess of that required to sediment even the small $20 \mathrm{~nm}$ spheres failed to produce cluster formation. These observations lead us to believe that the Dane particles and the tubules are held together by an antibody different from that which aggregates the small spheres and suggests, as Field and Cossart (1971) have done, that they possess an antigen not evident on the small spheres.

In the two patients with serum hepatitis the small spheres appeared as aggregates early in one and late in the other. Dane particles were seen in the serial samples in only one of the patients and then mainly in aggregates. In both patients the Australia antigen was cleared from the blood after 47 and $<252$ days respectively, a phenomenon mentioned by Wright (1972) and presumed by Dudley, Fox, and Sherlock (1972) to be evidence of a normal immune response.

Whatever the nature and the significance of the large particles resembling the paramyxoviruses or the coronaviruses (Zuckerman, Taylor, and Almeida,
1970) it may be important that they were not only seen frequently, often in aggregates, in the three individual samples without easily demonstrable Australia antigen particles, but that they were also commonly seen in small numbers in many of the other 47 plasma samples.

Since none of the 50 blood donors were aware of any previous illness associated with jaundice before being accepted onto the donor panel, the presence of Australia antigen in their sera suggests that the primary infection was a subclinical one. The role of persistent antigen in the blood of these chronic carriers is still uncertain but in the light of the high incidence of Dane particles and immune complexes, careful evaluation is deemed important on account of their possible participation in the pathogenesis of tissue damage. Singleton, Fitch, Merrill, Kohler, and Rettburg (1971) emphasized that the majority of such blood donors had histological evidence of liver disease and Ricci, De Bac, and Caramia (1972) confirmed this with liver biopsies which showed the presence of liver damage in all of six clinically normal carriers.

The association of these antigenic elements with various forms of liver disease has been reported frequently, but, although the Australia antigen carrier may still be infective, evidence of liver damage is not an inevitable result (Krugman and Giles, 1970). There may be no clinical evidence of disease in some individuals even after many years of persistent carriage (Zuckerman and Taylor, 1969) or when the antigen in the serum is abundant (Dudley, Fox, and Sherlock, 1971). To Dudley et al (1972) these observations indicate that the liver cell damage and the clinical course is more likely to be dependent upon the host responses than to the presence of the infective agent alone.

Immune complexes of Australia antigen have been thought to play a part in damage to the liver and in the development of certain extrahepatic lesions. Gocke, Hsu, Morgan, Bombardieri, Lockshin, and Christian (1970) and Trepo and Thivolet (1970) have reported vascular lesions (polyarteritis nodosa) with mild hepatic damage in patients with demonstrable Australia antigen in the vessel walls. Membranous glomerulonephritis was reported by Combes, Stastny, Shorey, Eigenbrodt, Barrera, Hull, and Carter (1971) which they attributed to the deposition of immune complexes in the glomerular membranes. In a patient with liver damage running a fulminating course, Almeida and Waterson (1969) showed that large amounts of antibody separating aggregated particles were present but Wright (1972) was unable to find a close correlation between the type or chronicity of the liver disease and the presence of immune complexes as seen by electron 
microscopy, while Prince and Trepo (1971) could not correlate the presence of such complexes with the presence or absence of chronic active hepatitis or polyarteritis nodosa.

The removal of these well meaning members of the community from the donor panel should be accompanied by the encouragement to seek whatever benefits clinical or further laboratory investigations have to offer.

We wish to thank Dr E. R. Rudman of the Western Province Blood Transfusion Service for supplying the samples of plasma from the blood donors.

\section{References}

Almeida, J. D. (1972). Individual morphological variations seen in Australia antigen positive sera. Amer. J. Dis. Child., 123, 303-308.

Almeida, J. D., Rubenstein, D., and Stott, E. J. (1971). New antigenantibody system in Australia-antigen-positive hepatitis. Lancet, 2, 1225-1227.

Almeida, J. D., and Waterson, A. P. (1969). Immune complexes in hepatitis. Lancet, 2, 983-986.

Almeida, J. D., Waterson, A. P., Trowell, J. M., and Neale, G. (1970). The finding of virus-like particles in two Australia antigen positive livers. Microbios, 2, 145-153.

Almeida, J. D., Zuckerman, A. J., Taylor, P. E., and Waterson, A. P. (1969). Immune electron microscopy of Australia-SH (serum hepatitis) antigen. Microbios., 1, 117-123.

Bayer, M. E., Blumberg, B. S., and Werner, B. (1968). Particles associated with Australia antigen in the sera of patients with leukaemia, Down's syndrome and hepatitis. Nature (Lond.), 218, 1057-1059.

Combes, B., Stastny, P., Shorey, J., Eigenbrodt, E. H., Barrera, A.,
Hull, A. R., and Carter, N. W. (1971). Glomerulonephritis $\frac{2}{\overrightarrow{7}}$ with deposition of Australia antigen-antibody complexes in 은 glomerular basement membrane. Lancet, 2, 234-237.

Dane, D. S., Cameron, C. H., and Briggs, M. (1970). Virus-like $\overrightarrow{\bar{\omega}}$ particles in serum of patients with Australia antigen-associated hepatitis. Lancet, 1, 695-698.

Deutsch, G. F., and Spence, L. (1972). Virus-like particles in the liver and their relationship to Australia antigen. Lancet, 1, 447.

Dudley, F. J., Fox, R. A., and Sherlock, S. (1971). Relationship of $\frac{\mathcal{S}}{\partial}$ hepatitis-associated antigen (H.A.A.) to acute and chronic $\frac{\mathbb{D}}{2}$ liver injury. Lancet, 2, 1-3.

Dudley, F. J., Fox, R. A., and Sherlock, S. (1972). Cellular immunity and hepatitis-associated Australia antigen liver disease. Lancet, $\rightarrow$ 1, 723-726.

Field, A. M., and Cossart, Y. E. (1971). Specificity of Au antibcdies. Lancet, 2,91.

Gocke, D. J., Hsu, K., Morgan, C., Bombardieri, S., Lockshin, M. and Christian, C. L. (1970). Association between polyarteritis and Australia antigen. Lancet, 2, 1149-1153.

Krugman, S., and Giles, J. P. (1970). Viral hepatitis: new light on an old disease. J. Amer. med. Ass., 212, 1019-1029.

Prince, A. M., and Trepo, C. (1971). Role of immune complexes $\omega$ involving $\mathrm{SH}$ antigen in pathogenesis of chronic active hepa- $\mathrm{N}$ titis and polyarteritis nodosa. Lancet, 1, 1309-1312.

Ricci, G., De Bac, C., and Caramia, F. (1972). Liver disease in Australia antigen carriers. Lancet, 1, 494.

Singleton, J. W., Fitch, R. A., Merrill, D. A., Kohler, P. F., and Rettberg, W. A. H. (1971). Liver disease in Australia-antigenpositive blood donors. Lancet, $2,785-787$.

Trepo, C., and Thivolet, J. (1970). Hepatitis associated antigen and periarteritis nodosa. Vox Sang. (Basel), 19, 410-411.

Wright, R. (1972). Chronic hepatitis. Brit. med. Bull., 28, 120-124.

Zalan, E., Hamvas, J. J., Tobe, B. A., Kuderewko, O., and Labzoffoky, N. A. (1971). Association of virus-like particles $\underset{W}{ }$ with Australia antigen in serum of patients with serum hepatitis. Canad. med. Ass. J., 104, 145-147.

Zuckerman, A. J., and Taylor, P. E. (1969). Persistence of the serum hepatitis (SH-Australia) antigen for many years. Nature (Lond.), 223, 81-82.

Zuckerman, A. J., Taylor, P. E., and Almeida, J. D. (1970). Presence of particles other than the Australia-SH antigen in a case of chronic active hepatitis with cirrhosis. Brit. med. J., 1, 262-264.@ 